\title{
Development of a Medical Spanish Curriculum for Fourth-Year Medical Students
}

\author{
Arhanti Sadanand, MD | Mark H. Ryan, MD | Steven Cohen, DrPH, MPH | Michael S. Ryan, MD, \\ MEHP
}

PRIMER. 2018;2:17.

Published: 9/11/2018 | DOI: 10.22454/PRiMER.2018.738688

\section{Abstract}

Introduction: The US Latino population is projected to double over the next 50 years while the proportion of Latino physicians is expected to decrease over the same interval. Spanish curricula within medical schools are common but rarely assess learners for proficiency and are often not incentivized. Family physicians are well positioned to promote the effective delivery of culturally and linguistically appropriate care to Latino patients with limited English proficiency (LEP). Our aim was to develop a replicable, incentivized, medical Spanish curriculum to promote fluency.

Methods: We developed a peer-taught, interactive, case-based medical Spanish curriculum for fourth-year medical students at a single medical school. All fourth-year medical students were eligible to enroll. Seventeen students completed pre- and postintervention questionnaires to rate their self-efficacy in medical Spanish comprehension and vocabulary. At the end of the course, students were also assessed for oral Spanish language skills by a standardized patient (SP).

Results: Students rated themselves as having improved at completing nearly all components of the medical interview and physical in Spanish after completing the course $(15 / 16$ tasks, $P<0.001)$.

Conclusion: This peer-led medical Spanish course shows promise as a feasible and sustainable curriculum for teaching medical Spanish and assessing fluency among fourth-year medical students. Establishing a cohort of peers as teachers addresses concerns about cost and reduces the need for faculty support.

\section{Introduction}

The Spanish-speaking population in the United States is projected to double over the next 50 years. ${ }^{1}$ Less than $6 \%$ of non-Hispanic white physicians report speaking Spanish compared to $69 \%-92 \%$ of Latino physicians; however, the Latino physician rate has fallen over the last 30 years. ${ }^{2}$ Language discordance between patients and providers has been linked to more adverse events, longer hospital stays, decreased access to care, and poorer quality of care. ${ }^{3-5}$ Family medicine's patient-centered, biopsychosocial approach to care is amenable to important medical and cultural considerations within LEP groups, in which language has been noted to be a significant barrier to effective care. ${ }^{6}$

One solution to the dearth of Spanish-speaking physicians involves Spanish training in medical school. A 2015 survey found that $66 \%$ of US medical schools offered curricula to develop Spanish speaking skills. A majority used multiple teaching styles and involved patient encounters. However, many of these programs lacked formal assessment of oral language proficiency, and only $62 \%$ incentivized participation with school credit. ${ }^{7}$ Credit for participation may be viewed as an important incentive for learners who must weigh the relative merits of limited 
elective time within their medical school curriculum.

We used a framework for curriculum development in medical education and a medical Spanish text to develop a peer-led, interactive, credit-based medical Spanish course for fourth-year medical students including an oral assessment of medical Spanish fluency (Table 1) ${ }^{8,9}$ Our purpose was to improve students' self-efficacy and fluency in medical Spanish. The goal of this peer-led program was to overcome disadvantages inherent in faculty-led curricula including recruitment, hiring, and compensation. Near-peer teaching has been shown to create a favorable learning environment and offer education to students on their own cognitive level. ${ }^{11}$

\section{Methods}

The curriculum (Table 2) was piloted at Virginia Commonwealth University (VCU) School of Medicine (SOM), a public university located in Richmond, Virginia. The VCU SOM enrolls approximately 200 students in each matriculating class, of which approximately $3 \%$ identify as Hispanic, Latino, or of Spanish origin. Richmond currently has a population of approximately 250,000 , and recent projections suggest the Hispanic population will grow to nearly 90,000 in the next 20 years. ${ }^{12}$

We identified a Spanish-fluent faculty member (M.H.R.) with prior experience developing a medical Spanish course to serve as an advisor. The Office of Student Affairs provided oversight for student registration and credit for course completion. Two volunteer peer instructors with nonnative Spanish fluency taught the course. Both participated in the development of content and instructional methods used in the curriculum. The advisor knew the instructors' level of Spanish proficiency. No incentives were provided to instructors. The course and its curriculum were reviewed and approved by the VCU SOM Curriculum Council.

Learner enrollment was solicited by email. All fourth-year medical students $(n=192)$ were eligible to participate regardless of level of Spanish proficiency. Participation was incentivized using elective course credit that could be used toward graduation requirements. The course was offered in two separate 4-week elective blocks, for a total classroom time of 12 hours per block.

To assess the impact of the curriculum, a single group pretest/posttest design was used. We developed a survey to rate self-efficacy for each of the curricular objectives using a Likert-type scale. ${ }^{13}$ Free-response questions allowed students to elaborate on prior Spanish education and deliver feedback. The content of the survey was developed to mirror the objectives but was not formally validated. We also wrote a single-case Objective Structured Clinical Examination (OSCE) using a certified medical Spanish interpreter as the SP. The interpreter provided verbal feedback and formally assessed student performance using the Student Oral Language Observation Matrix (SOLOM), ${ }^{14}$ a fiveitem instrument designed to rate students' comprehension, fluency, vocabulary, pronunciation, and grammar on a four-point scale ( 1 indicating poor performance and 4 indicating optimal performance). The OSCE was conducted the day after the final classroom session, and the survey was due within 1 week of course completion. The VCU Institutional Review Board granted the study exemption.

\section{Results}

Twenty learners were divided equally between males and females. Seventy-five percent $(n=15)$ had some background in Spanish while 25\% $(n=5)$ had never taken any Spanish classes. Of those who had a background in Spanish language, $67 \%$ had completed high school-level coursework.

Paired $t$-tests were used to examine statistical differences between pretest and posttest scores. Statistical significance was set to $P<0.05$. IBM SPSS version 24 (Armonk, NY) was used for all statistical analyses. All participants who completed both surveys $(n=17)$ reported improved medical Spanish ability across all abilities. The mean score across all pretest abilities was 1.60 (SD: 0.64) and the mean score across all posttest abilities was 3.38 (SD: 0.56; Figure 1). Significant improvements $(P<0.001)$ in ability were made in all categories except for introductions $(P=0.086)$. Students also reported improved confidence at performing all aspects of a history and physical, with mean improvement across all queried domains of 1.39 (SD 1.13; Figure 2). 
Fourteen students participated in the SP encounter. There was no statistically significant correlation between subject postest rating of ability and subject SP score (using Spearman rank). There were no significant differences in SP encounter scores between the two blocks across all five domains.

In written feedback, students praised the variety of educational strategies and the authenticity of the SP encounter. They requested more class sessions and more time discussing cultural determinants of health. All students reported that it would be helpful to have some Spanish knowledge prior to taking the class.

\section{Conclusions}

Students who participated in the pilot curriculum had improved self-ratings and demonstrated markers of Spanish fluency in an SP case. The use of near-peer instructors coupled with provision of elective credit may help facilitate participation and overcome barriers previously cited in similar courses. ${ }^{7,15}$

Students' average self-confidence ratings at medical Spanish tasks improved but did not reach the maximum score by the end of the class, suggesting an honest self-assessment. We suspect the SP encounter allowed students to reflect on their abilities; however, having the SP feedback prior to completing their evaluation of the course may have influenced these ratings of self-confidence. Accurate self-assessment of fluency is extremely important, as overestimation may lead physicians to undertake encounters without medical interpreters, cause medical errors, and damage the physician-patient relationship. ${ }^{16-18}$ Because of this issue, we emphasized the importance of considering one's own limitations and recognizing when certified interpreter services are warranted, especially for those who completed the curriculum.

Reuland et al suggest that the optimal medical Spanish curriculum is longitudinal, tailored to individuals' Spanish proficiency, and contains immersion activities. ${ }^{19}$ We aimed to develop a course that could meet these criteria with time and support. After the success of this pilot program, we incorporated mandatory, longitudinal use of language learning software as a complement to classroom-based teaching. We hope that as student participation increases, we can specifically tailor blocks to students' preexisting Spanish proficiency.

Our small sample size limits our ability to conduct multivariate analysis and adjust for confounders. We were unable to compare the group that received peer teaching with a control faculty-led group. In addition, implementation at our single institution limits the ability to generalize to other sites. We hope that repeat iterations of this course can find correlation between subjective self-rating of medical Spanish ability and SP ratings. We recognize that a major limitation of this study is the reliance on a nonvalidated self-assessment survey for the majority of our data. Our hope is that with repeat iterations of this course, instructors could gather data on internal consistency of our survey instrument and calculate interrater reliability from repeated SP assessments.

In future years, the curriculum will be strengthened by a preintervention oral examination and increased focus on the diverse groups that comprise Latino culture. Our chapter of the Latino Medical Students' Association helped us identify volunteer instructors in advance of upcoming academic years and will continue to sponsor and sustain the elective. We lacked objective assessment of the fluency of our instructors; longitudinal comparisons of instructor fluency and student outcomes are ripe for further investigation. Other instructor characteristics such as enthusiasm for material and engagement with students may also affect performance; however, these variables are more difficult to capture.

Working to improve Spanish language proficiency amongst future providers and to minimize language discordance has increasing importance due to the growing Latino LEP population and the association of language discordance with adverse outcomes. We believe other medical schools can adapt our curriculum to teach a larger cohort of medical students and improve outcomes for future patients.

\section{Tables and Figures}


Table 1: Application of Kern and Colleagues' Six Steps of Curriculum Development to Spanish for Medical Professionals Course Development

\begin{tabular}{|c|c|}
\hline Step & Approach \\
\hline $\begin{array}{l}\text { 1. Problem identification and } \\
\text { needs assessment }\end{array}$ & $\begin{array}{l}\text { - Reviewed literature on language discordance and outcomes, as well as statistics of Spanish- } \\
\text { speaking/LEP populations } \\
\text { - Reviewed survey of nationwide medical Spanish curricula to determine gaps } \\
\text { - Surveyed fourth-year students to assess demand for medical Spanish course }\end{array}$ \\
\hline $\begin{array}{l}\text { 2. Needs assessment of } \\
\text { targeted learners }\end{array}$ & - Learners established personal goals and objectives for the class \\
\hline $\begin{array}{l}\text { 3. Goals and specific } \\
\text { measurable objectives }\end{array}$ & $\begin{array}{l}\text { - Created goals and specific measurable objectives (that could be achievable in the allotted time } \\
\text { frame) based on readings from a medical Spanish text } \\
\text { - Recognize common chief complaints and identify body parts in Spanish } \\
\text { - Select appropriate questions to elicit a history of present illness in Spanish } \\
\text { - Examine recommendations for culturally competent care for Latino patients } \\
\text { - Demonstrate understanding of diverse cultural beliefs }{ }^{10} \\
\text { - Facilitate a cross-cultural interview through discussion with his/her classmates }{ }^{10}\end{array}$ \\
\hline 4. Educational strategies & $\begin{array}{l}\text { - Selected an array of educational strategies that relied upon motivated adult learners } \\
\text { - Written and oral comprehension of target vocabulary was learned, assessed, and reviewed each } \\
\text { session } \\
\text { - Standardized patient (SP) encounter was used as motivation to hone skills as well as opportunity } \\
\text { to practice with nonbiased listener }\end{array}$ \\
\hline 5. Implementation & $\begin{array}{l}\text { - Course sessions were conducted twice, once each in two separate blocks, with feedback offered } \\
\text { by two groups of students } \\
\text { - The addition of a second instructor led to variability in teaching but also allowed instructors to } \\
\text { gain insight and learn from each other }\end{array}$ \\
\hline 6. Evaluation and feedback & $\begin{array}{l}\text { - Student evaluations collected following the SP session } \\
\text { - Poster presentation to elicit feedback at school-wide conference for capstone projects pertaining } \\
\text { to serving needs of underserved communities } \\
\text { - Presentation to Curriculum Council to elicit feedback and request addition to Electives Catalogue } \\
\text { - Meetings with medical school deans and Latino Medical Student Association leadership to } \\
\text { determine future directions }\end{array}$ \\
\hline
\end{tabular}

Table 2: Medical Spanish Curriculum Design

\begin{tabular}{|c|c|}
\hline Time and duration & $\begin{array}{l}\text { - Two elective blocks (two 4-week periods) in spring } 2016 \\
\text { - Two } 90 \text {-minute classes held twice weekly over each block (total classroom time of } 12 \text { hours per block) } \\
\text { - Classes were held in the afternoon } \\
\text { - Receiving elective course credit requires attendance at }>75 \% \text { of course sessions }\end{array}$ \\
\hline $\begin{array}{c}\text { Instructor } \\
\text { characteristics }\end{array}$ & $\begin{array}{l}\text { - Minimum of } 5 \text { years of formal Spanish education } \\
\text { - Completion of }>4 \text { months of immersion programs in Spanish-speaking countries } \\
\text { - Participation in medical brigade groups to Latin American countries } \\
\text { - Volunteer work at health clinics serving predominantly Spanish-speaking patients within the Richmond } \\
\text { area }\end{array}$ \\
\hline Session activities & $\begin{array}{l}\text { - Define relevant vocabulary } \\
\text { - Interpret case-based dialogues } \\
\text { - Doctor-patient role play in clinical vignettes }\end{array}$ \\
\hline Instructional methods & $\begin{array}{l}\text { - Partnered dialogues, group discussions, role-play, educational games, individual activities, and teach- } \\
\text { back used in different sections of the classes to reflect a multitude of learning preferences } \\
\text { - Vocabulary quizzes and interactive games to improve retention and reiterate target material }\end{array}$ \\
\hline Clinical scenarios & $\begin{array}{l}\text { - Hypertension } \\
\text { - Diabetes } \\
\text { - Respiratory infections } \\
\text { - Abdominal/Gl complaints } \\
\text { - Musculoskeletal complaints } \\
\text { - Pregnancy/gynecologic complaints } \\
\text { - Full adult history and physical } \\
\text { - General pediatric interview and exam }\end{array}$ \\
\hline
\end{tabular}


Figure 1: Comparison of Pre- and Postelective Abilities in Medical Spanish

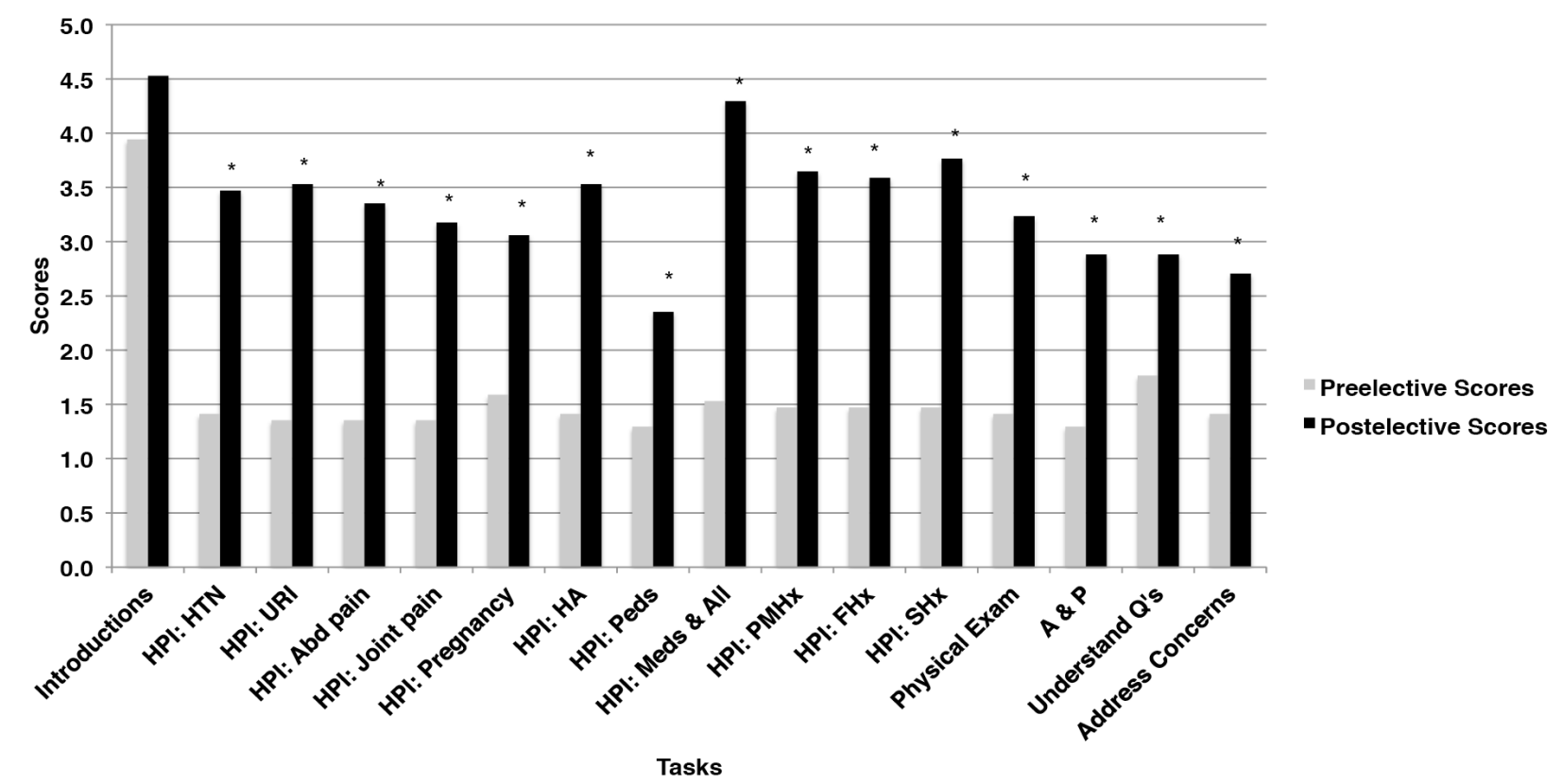

${ }^{*} P<0.001$.

Abbreviations: HPI, history of present illness; HTN, hypertension; URI, Upper Respiratory Infection; Abd, abdominal; HA, headache; Peds, paediatric; Meds \& All, Meds and Allergies; PMHx, past medical history; FHx, family history; SHx, social history; A\&P, assessment and plan; Q's, questions.

Scale: 1 , strongly disagree; 2 , disagree; 3 , neutral; 4 , agree; 5 , strongly agree.

Figure 2: Comparison of Pre- and Postelective Confidence in Medical Spanish

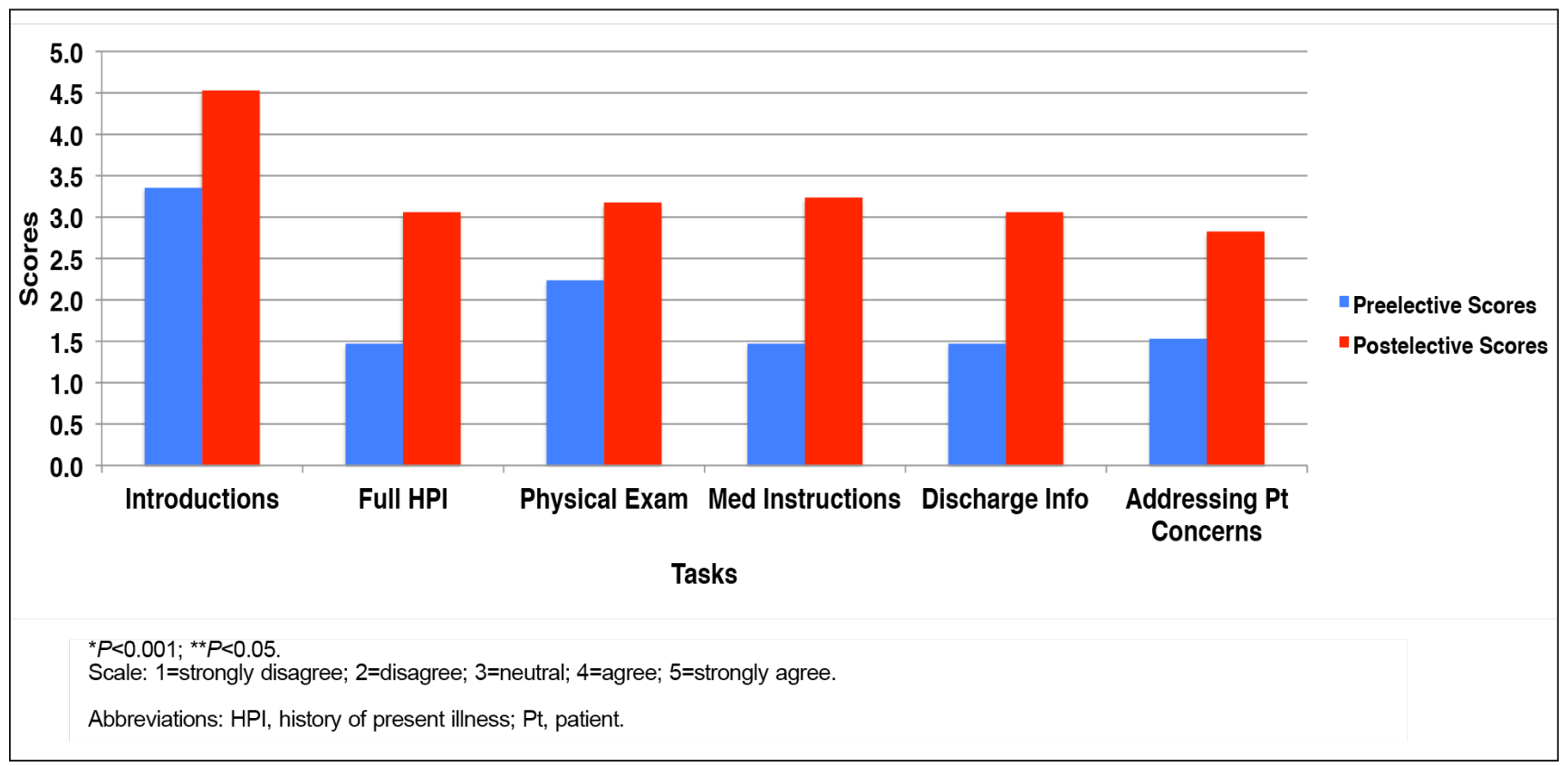

\section{Acknowledgments}

The authors gratefully acknowledge the contributions of Bryan Castro, Mary Lee Magee, Dr Patrick Lam, Dr Deborah Me, Dr Irving Phillips, and Dr Christopher Woleben to this project.

\section{Presentations:}

Sadanand A, Ryan MH. Spanish for medical professionals: creating a case-based curriculum. Poster presented at 
the STFM Conference on Medical Student Education. Anaheim, CA, February 9-12, 2017.

Sadanand A. Spanish for medical professionals: dynamic, interactive language teaching. Poster presented at the Capstone Reception for the International, Inner City, and Rural Preceptorship Program. Richmond, VA, April, 2016.

\section{Corresponding Author}

Arhanti Sadanand, MD

1 Children's PI, St Louis, MO 63110. 314-335-0914

arhanti@wustl.edu

\section{Author Affiliations}

Arhanti Sadanand, MD - Washington University School of Medicine, St Louis, MO

Mark H. Ryan, MD - Virginia Commonwealth University School of Medicine, Richmond, VA

Steven Cohen, DrPH, MPH - University of Rhode Island, Kingston, RI

Michael S. Ryan, MD, MEHP - Virginia Commonwealth University School of Medicine, Richmond, VA

\section{References}

1. Colby SL, Ortman JM. Projections of the size and composition of the US population: 2014 to 2060. Washington, DC: US Census Bureau; 2015. https://www.census.gov/content/dam/Census/library/publications /2015/demo/p25-1143.pdf. Accessed August 27, 2018.

2. Sánchez G, Nevarez T, Schink W, Hayes-Bautista DE. Latino physicians in the United States, 1980-2010: A thirty-year overview from the censuses. Acad Med. 2015;90(7):906-912. https://doi.org/10.1097 /ACM.0000000000000619

3. Divi C, Koss RG, Schmaltz SP, Loeb JM. Language proficiency and adverse events in US hospitals: a pilot study. Int J Qual Health Care. 2007;19(2):60-67. https://doi.org/10.1093/intqhc/mzl069

4. John-Baptiste A, Naglie G, Tomlinson G, et al. The effect of English language proficiency on length of stay and in-hospital mortality. J Gen Intern Med. 2004;19(3):221-228. https://doi.org/10.1111

/j.1525-1497.2004.21205.x

5. Pippins JR, Alegría M, Haas JS. Association between language proficiency and the quality of primary care among a national sample of insured Latinos. Med Care. 2007;45(11):1020-1025. https://doi.org/10.1097 /MLR.0b013e31814847be

6. Juckett G. Caring for Latino patients. Am Fam Physician. 2013;87(1):48-54.

7. Morales R, Rodriguez L, Singh A, et al. National survey of medical Spanish curriculum in US medical schools. J Gen Intern Med. 2015;30(10):1434-1439. https://doi.org/10.1007/s11606-015-3309-3

8. Kern DE. Curriculum Development for Medical Education: A Six-Step Approach. Baltimore, MD: Johns Hopkins University Press; 1998.

9. Ríos J, Torres JF. McGraw-Hill's Complete Medical Spanish. New York: McGraw-Hill; 2010.

10. Association of American Medical Colleges. Cultural competence education for medical students. http://www.aamc.org/meded/tacct/culturalcomped.pdf. Accessed December 29, 2015.

11. Ten Cate O, Durning S. Peer teaching in medical education: twelve reasons to move from theory to practice. Med Teach. 2007;29(6):591-599. https://doi.org/10.1080/01421590701606799

12. University of Virginia Weldon Cooper Center for Public Service. Virginia population projections. www.demographics.coopercenter.org/virginia-population-projections/. Accessed August 27, 2018.

13. Sadanand A. Development of a medical spanish curriculum for fourth year medical students. STFM Resource Library. https://resourcelibrary.stfm.org/viewdocument/supplemental-materials-medicalsp?CommunityKey=2751b51d-483f-45e2-81de-4faced0a290a. Accessed August 27, 2018.

14. Montebello Unified School District Instructional Division. Student Oral Language Observation Matrix (SOLOM). Montebello, CA: Montebello Unified School District; 1978.

15. Nelson AJ, Nelson SV, Linn AM, Raw LE, Kildea HB, Tonkin AL. Tomorrow's educators ... today? Implementing near-peer teaching for medical students. Med Teach. 2013;35(2):156-159. https://doi.org/10.3109 
/0142159X.2012.737961

16. Flores G, Mendoza FS. Dolor aquí? Fiebre?: a little knowledge requires caution. Arch Pediatr Adolesc Med. 2002;156(7):638-640. https://doi.org/10.1001/archpedi.156.7.638

17. Diamond LC, Tuot DS, Karliner LS. The use of Spanish language skills by physicians and nurses: policy implications for teaching and testing. J Gen Intern Med. 2012;27(1):117-123. https://doi.org/10.1007 /s11606-011-1779-5

18. Flores G, Laws MB, Mayo SJ, et al. Errors in medical interpretation and their potential clinical consequences in pediatric encounters. Pediatrics. 2003;111(1):6-14. https://doi.org/10.1542/peds.111.1.6

19. Reuland DS, Frasier PY, Slatt LM, Alemán MA. A longitudinal medical Spanish program at one US medical school. J Gen Intern Med. 2008;23(7):1033-1037. https://doi.org/10.1007/s11606-008-0598-9

Copyright (c) 2018 by the Society of Teachers of Family Medicine 